\title{
A destruição da natureza e a emergência de zoonoses: os temas híbridos e o contrato natural podem nos mostrar caminhos para superar problemas?
}

The destruction of nature and the emergence of zoonoses: can hybrid themes and the natural contract show us ways to overcome problems?

Prof. Dr. Rogério Tolfo

Universidade Estadual de Santa Cruz - UESC

tolfo72@gmail.com

Orcid: https://orcid.org/00000003-1807-190X

Data de recebimento: $26 / 08 / 2020$ Data de aceite: $08 / 10 / 2020$

\section{Resumo}

Apresentaremos, inicialmente, em linhas gerais, a partir de artigos que versam sobre o transbordamento - a passagem de vírus de outros animais para o homem - a relação entre destruição ambiental e o possível aumento de zoonoses. Em um segundo momento, exporemos tanto a ideia de híbrido presente em Jamais fomos Modernos de Bruno Latour, quanto à ideia de um contrato natural, tal qual presente na obra O Contrato Natural de Michel Serres. Tais ideias podem auxiliar a compreensão de questões e práticas humanas atuais, possibilitando tanto o surgimento de um novo modo de tratar nossas questões, quanto uma mudança de nossa relação com o ambiente natural.

Palavras-chave: Destruição Ambiental, Zoonoses, Híbrido, Contrato Natural.

\section{Abstract}

We will initially present, in general lines, from articles that deal with overflow - the passage of viruses from other animals to man - the relationship between environmental destruction and the possible increase in zoonoses. In a second step, we will expose, both the idea of hybrid present in We Have Never Been Modern by Bruno Latour, as well as the idea of a natural contract, as present in the work The Natural Contract by Michel Serres. Such ideas can help to understand current human issues and practices, enabling both the emergence of a new way of dealing with our issues and a change in our relationship with the natural environment.

Keywords: Environmental Destruction, Zoonoses, Hybrid, Natural Contract. 


\section{Introdução}

Inicialmente, apresentaremos as ideias gerais de três artigos que tratam da questão do avanço das atividades humanas em áreas de vegetação natural e sua relação com zoonoses. Nossa meta é mostrar que há estudos que estabelecem a relação entre destruição de áreas de vegetação natural - tanto vegetação florestal, quanto não florestal - e aumento do risco de zoonoses. Alguns artigos consultados foram Global shifts in mammalian population trends reveal key predictors of virus spillover risk - Mudanças globais nas tendências da população de mamíferos revelam preditores chave do risco de disseminação de vírus (nossa tradução); Bats, coronaviruses, and deforestation: Toward the emergence of novel infectious diseases - Morcegos, coronavírus e desmatamento: em direção ao surgimento de novas doenças infecciosas? (nossa tradução); e Por que o Brasil precisa de suas reservas legais.

Em seguida, exporemos a tese de temas híbridos de Latour com o objetivo de apontar para o fato de que um problema que se mostra híbrido, não pode ser separado para ser tratado, mas deve considerar os conjuntos distintos que o envolvem e que leva Latour, ao final do capítulo 1, intitulado Crise, a formular as perguntas: "Seria necessária uma outra democracia? Uma democracia estendida às coisas?" (LATOUR, 1994, p. 17)

Visamos também apresentar a proposta de Serres, sobre a necessidade de um novo pacto/contrato que considere a natureza, o mundo, como parte do referido contrato. Veremos que o autor propõe que se acrescente ao contrato social (contratualismo), um contrato natural de simbiose e reciprocidade, tornando a natureza sujeito de direito.

\section{Destruição da natureza e zoonoses}

Em 8 de abril de 2020, isto é, no período da pandemia ocasionada pelo coronavírus covid19, foi publicado o artigo Mudanças globais nas tendências da população de mamíferos revelam preditores chave do risco de disseminação de vírus, de Christine K. Johnson e outros autores, na Revista The Royal Society, de um estudo que estabelece relação entre mudanças globais, mamíferos e zoonoses (risco de transbordamento de vírus de outros animais para humanos). Não é nosso objetivo discorrer ampla e minuciosamente sobre o presente artigo e sobre os demais que serão aqui apresentados, mas, apenas expor algumas ideias destes textos que revelam uma estreita ligação entre os seguintes temas: questões ambientais e aumento de zoonoses.

O estudo forneceu novas evidências (JOHNSON, 2020, p. 1) que permitem avaliar o risco de transbordamento de vírus de mamíferos para humanos. O estudo também forneceu evidências de que a exploração e as atividades antropogênicas no habitat de animais selvagens facilitam a transmissão de doenças zoonóticas. "Entre as espécies de vida selvagem ameaçadas, aqueles com redução populacional devido à exploração e perda de habitat compartilharam mais vírus com os seres humanos" (JOHNSON, 2020, p. 1). Conforme a citação, a redução populacional não significa diminuição de risco de transbordamento. Ao contrário, aumenta este risco porque permite novos contatos entre humanos e animais selvagens. Vejamos outro artigo sobre os temas em questão.

Em Por que o Brasil precisa de suas reservas legais, os autores (METZGER et al., 2019, p. 111) afirmam que transformar áreas de vegetação natural - tanto vegetação florestal, quanto não florestal - aumenta o risco de zoonoses. Os exemplos, presentes no item Controle de zoonoses e saúde humana, do aumento de doenças vão desde a expansão prevista do plantio de cana de açúcar em São Paulo ao aumento da malária na floresta Amazônica.

Esses poucos exemplos mostram que a redução do desmatamento é a melhor maneira para controlar zoonoses como malária, hantavírus, febre amarela, entre outras, e que a perda maciça de cobertura vegetal natural pode ter enormes impactos não só sobre a saúde pública, mas também para a economia (METZGER et al., 2019, p. 111). 
Outro artigo, Morcegos, coronavírus e desmatamento: em direção ao surgimento de novas doenças infecciosas? (AFELT et al., 2018), afirma que há aumento do risco de surgimento de nova doença de morcego $\mathrm{CoV}$ como consequência das mudanças e pressões ambientais. Referindo-se ao Sudoeste Asiático, região do mundo com maior taxa de desmatamento, aponta o vínculo do desmatamento ao aumento da área agrícola $\mathrm{e}$ crescimento urbano desordenado. Ainda de acordo com o referido artigo, existe a crença de que "o desmatamento e a antropização levarão ao desaparecimento de espécies" (AFELT et al., 2018, p. 2), o que nem sempre é verdade, porque os ambientes humanos podem proporcionar habitat aceitável ao morcego, favorecendo a maior concentração e biodiversidade de vírus.

Isso aumenta o risco de transmissão de vírus por contato direto, infecção por animais domésticos ou contaminação por urina ou fezes. Sendo os CoVs principalmente agentes de doenças veterinárias, o risco de surgimento de doenças é tanto nas doenças de animais domésticos quanto nas humanas (AFELT et al., 2018, p. 2).

O item intitulado Vírus transmitidos por morcegos: um inimigo histórico com um futuro brilhante é por si só muito elucidativo, da posição dos autores. Nesta perspectiva, afirmam na conclusão que a criação de condições favoráveis em ambientes humanos pode representar uma ameaça significativa para o futuro.

Apresentadas as ideias destes artigos, e há muitos artigos sobre o referido assunto, por exemplo: Deforestation and Malaria in Mâncio Lima County, Brazil e Abundance of impacted forest patches less than $5 \mathrm{~km} 2$ is a key driver of the incidence of malaria in Amazonian Brazil, passaremos à próxima etapa de nosso trabalho, a questão do híbrido em Latour.

\section{Híbridos de natureza e cultura}

Bruno Latour inicia seu livro Jamais fomos Modernos com a apresentação de inúmeros temas que aparecem na leitura de um jornal. O subtítulo, no início do capítulo intitulado Crise, é A proliferação dos híbridos. Assim que encerra a exposição dos temas híbridos no jornal, afirma que:

Multiplicam-se os artigos híbridos que delineiam tramas de ciência, política, economia, direito, religião, técnica, ficção. Se a leitura do jornal diário é a reza do homem moderno, quão estranho é o homem que hoje reza lendo estes assuntos confusos. Toda cultura e toda a natureza são diariamente reviradas aí (LATOUR, 1994, p. 8).

Ao que parece (LATOUR, 1994, p.8) ninguém está preocupado com essa proliferação de artigos híbridos, de artigos que se cruzam entre si, ligando, por exemplo, covid19 e a comunidade de Paraisópolis, exemplo de organização contra a Covid19, segundo os meios de comunicação (uma rápida e simples busca no Google mostra muitas outras reportagens sobre o tema). Uma questão sanitária (natural, biológica e epidemiológica) diretamente ligada a uma questão de ineficiência e ineficácia de ações de cunho político-governamental (cultural, social e econômica), isto é, ciência e política estreitamente vinculadas.

Quando o caráter híbrido dos temas aparece - esta rede tênue entre questões de ordem político-social e problemas de ordem científico-natural que se mostra, que irrompe, dirá Latour - os especialistas (os analistas) tratam de separá-las, lidam com estas tramas e vínculos como se não existissem e, usando uma espada bem afiada, rompem o nó górdio, aquele nó que não pode ser desatado, e o navio fica sem rumo, tendo à sua esquerda o conhecimento e à sua direita a política.

[...] mas os analistas, os pensadores, os jornalistas e todos os que tomam decisões irão cortar a fina rede desenhada pelo vírus em pequenos compartimentos específicos onde encontraremos apenas ciência, apenas economia, apenas representações sociais, [...] (LATOUR, 1994, p. 8). 
A citação acima se refere a uma passagem do texto de Latour, na qual o autor discorre sobre o vírus da AIDS. Nosso exemplo é também de um vírus, do causador da pandemia, motivo do desenvolvimento deste artigo. Diferentes vírus, questões semelhantes.

Latour propõe que o nó górdio seja reatado. O referido autor faz parte do movimento denominado Science Studies. A expressão inglesa Science Studies se refere a todos aqueles que visam reatar o nó górdio, indo de um a outro destes conjuntos separados (com um corte, já que o nó não pode ser desfeito) com a afiada espada. $\mathrm{O}$ que caracteriza o Science Studies é, portanto, o híbrido. No entanto, o trabalho dos autodeclarados híbridos, que visam descrever as tramas (as teias; o enredo; a transação, a permuta) dos diversos conjuntos, não é compreendido com as categorias usuais dos especialistas. Tais categorias separam a natureza, a política e o discurso.

A partir de exemplos tais como a descrição do giroscópio realizada por Mackenzie, Latour afirma que tal pesquisa diz respeito antes ao "seu envolvimento com nossos coletivos e com os sujeitos", do que com a natureza, o conhecimento e a coisa-em-si (LATOUR, 1994, p. 9). No entanto, no âmbito das especialidades e dos especialistas se pensará que a pesquisa de Mackenzie se refere às técnicas e as ciências. Este é o primeiro mal-entendido dos críticos. O segundo mal-entendido é pensar que a proposta dos Science Studies reduz a verdade científica a interesses e manobras políticas (LATOUR, 1994, p. 10). O terceiro mal-entendido, afirma nosso autor, é que o trabalho dos híbridos diz respeito apenas ao discurso. Segundo Latour (1994, p. 10): "Contudo, não estamos falando do contexto social e dos interesses do poder, mas sim de seu envolvimento nos coletivos e nos objetos".

Após apontar (e brevemente explicar) os mal-entendidos, Jamais fomos Modernos visa mostrar que a crítica (as especialidades) está em crise. A crise das especialidades se instaura porque:

Os fatos científicos são construídos, mas não podem ser reduzidos ao social, porque ele está povoado por objetos mobilizados para construí-lo. O agente desta dupla construção provém de um conjunto de práticas que a noção de desconstrução capta da pior forma possível. O buraco de ozônio é por demais social e por demais narrado para ser realmente natural; as estratégias das firmas e dos chefes de Estado, demasiado cheias de reações químicas para serem reduzidas ao poder e ao interesse; o discurso da ecosfera, por demais real e social para ser reduzido a efeitos de sentido. Será nossa culpa se as redes são ao mesmo tempo reais como a natureza, narradas como o discurso, coletivas como a sociedade? (LATOUR, 1994, p. 12, grifo nosso).

Segundo o autor, é possível sair deste dilema, desde que seja alterada a definição do mundo moderno (LATOUR, 1994, p. 12-13), antropologizando o mundo moderno, o que seria possível com a alteração da própria definição de mundo moderno. Esta alteração é proposta a partir da abordagem de um fato histórico, a queda do muro de Berlim.

A queda do muro "simboliza a queda do socialismo", mas simboliza também,

[...] o fim do capitalismo e de suas vãs esperanças de conquista ilimitada e de dominação total da natureza. Ao tentar desviar a exploração do homem pelo homem para uma exploração do homem pela natureza, o capitalismo multiplicou indefinidamente as duas (LATOUR, 1994, p. 14).

Após essa abordagem, Latour afirma que a mesma faz com que os modernos percam um pouco da sua autoconfiança. Em seguida, apresenta a hipótese de que o termo moderno designa tanto o conjunto que cria híbridos de natureza e cultura, quanto o que cria as zonas ontológicas distintas de natureza e cultura. Finaliza o parágrafo apontando a interdependência dos dois conjuntos (LATOUR, 1994, p. 1).

Ser moderno é considerar estas duas práticas separadas. Deixamos de ser modernos se superamos esta separação. 
Ao mesmo tempo, deixamos de ter sido modernos, no pretérito, pois tomamos consciência, retrospectivamente, de que os dois conjuntos de práticas estiveram operando desde sempre no período histórico que se encerra (LATOUR, 1994, p. 16).

Por fim, Latour pergunta pelo laço existente entre os conjuntos e apresenta hipóteses, segundo suas palavras, ainda grosseiras e demasiado amplas. "Seria necessária uma outra democracia? Uma democracia estendida às coisas?” (LATOUR, 1994, p. 17). Com estas perguntas, é finalizado o capítulo aqui abordado de Jamais fomos Modernos.

Vimos que Latour encerra o capítulo estabelecendo, a partir de uma pergunta, uma possível relação entre natureza e cultura: democracia (um fenômeno social, humano, enfim, cultural) e as coisas (fenômeno natural). Em outras palavras, uma política que abarca também a natureza, uma política que não considera os fenômenos naturais separados dos fenômenos culturais.

Passaremos, a seguir, a apresentação do que Serres denomina de contrato natural, em contraponto com o contrato social da modernidade.

\section{Contrato Natural: um contrato de simbiose e reciprocidade}

Para os autores do contratualismo moderno, o homem sai de seu estado de natureza quando realiza um pacto, um contrato, a partir do qual forma a sociedade. Saímos do estado natural para a vida em sociedade a partir da instauração de um pacto, de um contrato. Este pacto é realizado entre os homens, isto é, a natureza não é considerada neste acordo. Podemos dizer que o contrato visa estabelecer regras e leis para reger as relações entre os seres humanos, no entanto, nada estabelece sobre a relação do homem com a natureza.

Um dos pontos para o qual aponta Serres é exatamente o da lacuna, em relação ao mundo/natureza, existente no contrato social. "Estranhamente lacônico acerca do mundo, esse contrato, dizem eles, fez-nos abandonar o estado natural para formar a sociedade" (SERRES, 1990, p. 60). O direito (SERRES, 1990, p. 61-62) para os seres que não o tem se refere a dois conjuntos e a necessidade de uma relação entre tais conjuntos: o conjunto natural e o conjunto humano e social. "Precisamos pensar, construir e colocar em prática um novo equilíbrio global entre estes dois conjuntos" (SERRES, 1990, p. 64). Neste pensar, entendido como próximo a compensar, está à base para um direito mais geral, denominado de contrato natural.

O contrato natural, acrescido ao contrato exclusivamente social, é entendido como um contrato de simbiose e reciprocidade, no qual a nossa relação com as coisas/natureza/mundo não equivaleria a uma relação parasitária, em que o domínio é um domínio que tudo tira e nada dá ao hospedeiro, mas a uma relação em que a natureza (hospedeiro) recebe tanto quanto fornece, sendo, portanto, considerada um sujeito de direitos.

O parasita agarra tudo e não dá nada; o hospedeiro dá tudo e não agarra nada. O direito de dominação e de propriedade reduz-se ao parasitismo. Pelo contrário, o direito de simbiose define-se pela reciprocidade: aquilo que a natureza dá ao homem é o que este deve dar a ela, tornada sujeito de direito (SERRES, 1990, p. 66)

Portanto, o que está em jogo é uma mudança na relação entre homem e natureza. A mudança de uma relação parasitária, portanto, de destruição do hospedeiro, para uma relação de reciprocidade. Com o exposto aqui, é possível passar as nossas reflexões conclusivas. 


\section{Considerações finais}

Os artigos acima apresentados que versam sobre meio ambiente e zoonoses têm, obviamente, a meta de mostrar que há uma relação entre desequilíbrio ambiental e o surgimento de zoonoses, consequentemente, de possíveis pandemias, tais como a que nos acomete neste momento. Consideramos muito difícil contestar tal relação e, para defendê-la ou contestá-la, não precisamos nem mesmo reatar o nó górdio, basta atentar para estudos especializados que mostram o aumento de zoonoses onde há destruição indiscriminada da vegetação natural. Não queremos afirmar com isso que o vínculo dos referidos estudos especializados com questões econômicas, políticas, sociais, etc., não é importante para a melhor compreensão do mundo que vivemos, ao contrário, tal aproximação nos permite ver com mais clareza a relação entre o surgimento de zoonoses e as causas destas zoonoses como, por exemplo, o avanço da agricultura e da pecuária, com objetivos meramente econômicos e lucrativos, em áreas preservadas.

Nesta perspectiva, entendemos que a aproximação entre os temas da natureza e da sociedade, de temas híbridos, é uma proposta a ser considerada seriamente. Os estudos sobre zoonoses, como vimos nos textos aqui expostos, vinculam a degradação do meio ambiente ao avanço das áreas de cultivo e pastagens. Então, perguntamos: como poderemos entender satisfatoriamente estas questões sem aproximar natureza e cultura, sem reatar os temas que tratam de viroses com os que tratam de política? Como melhor compreender estes âmbitos, separadamente, quando estão intrinsecamente ligados? Isso, no entanto, não significa (como afirmamos acima), que consideramos as especialidades e especialistas como algo que deve ser abandonado ou como algo desprovido de valor tanto no âmbito da ciência, quanto no âmbito da sociedade. Significa que, ao lado e concomitantemente aos estudos especializados, é importante o tratamento de questões políticas, sociais, econômicas e outras.

Entendemos que a especialização, o aprimoramento dos técnicos/especialistas, não é algo que deva ser recusado, destruído e destroçado. Não é isso que defendemos. O que defendemos é que ao lado da formação de profissionais especialistas se dê a formação de cidadãos e do pleno desenvolvimento da pessoa. No âmbito da educação no Brasil, nos seus diferentes níveis, entendemos que separação similar à separação de temas híbridos é evidente. Há uma preocupação clara com a formação de profissionais, de técnicos/especialistas, com pouca preocupação (nula ou mínima, em geral) com a questão da cidadania e do desenvolvimento pleno da pessoa, embora a própria constituição brasileira apregoe em seu artigo 205 que a educação visa o pleno desenvolvimento da pessoa, a preparação para o exercício da cidadania e a qualificação para o trabalho. Uma educação que efetivamente se desse deste modo, certamente evitaria inúmeros problemas, de diversas ordens.

O foco na qualificação para o trabalho, sem contemplar os demais aspectos da formação educacional, não traz prejuízos para a sociedade como um todo? Um doutor, por exemplo, em agronomia (professor ou não), que elogia e louva o agronegócio, sem ponderar os problemas provenientes desta atividade, contribui satisfatoriamente com a sociedade ou apenas com a produção e o lucro, enquanto gastos públicos e tantos outros problemas relacionados a esta atividade se multiplicam? Certamente, não. Ao contrário, muito provavelmente, contribui para o desprezo de comunidades tradicionais e sua cultura, por exemplo. Culturas com as quais, provavelmente, muito poderíamos (ou podemos?) aprender tanto em relação aos nossos tratamentos temáticos, quanto a nossa relação com a natureza. 


\section{Referências Bibliográficas}

AFELT, Aneta; FRUTOS, Roger; DEVAUX, Christian. Bats, Coronaviruses, and deforestation: Toward the emergence of novel infectious diseases. Frontiers in microbiology; Washington, v. 9, n. 702, p. 1-5, Abril 2018.

CHAVES, Leonardo Suveges Moreira; CONN, Jan E. ; LÓPEZ, Rossana Verónica Mendoza; SALLUM, Maria Anice Mureb. Abundance of impacted forest patches less than $5 \mathrm{~km} 2$ is a key driver of the incidence of malaria in Amazonian Brazil. Scientific Reports. Londres, v. 8, n. 7077, p. 1-11, Maio 2018.

JOHNSON, Christine K.; PETA, L. Hitchens; PRANAV, S. Pandit. Global shifts in mammalian population trends reveal key predictors of virus spillover risk. The Royal Society journal. Londres, v. 287, n. 1924, p. 1-10, April 2020.

LATOUR, Bruno. Jamais fomos modernos. Ensaio de antropologia simétrica. Rio de Janeiro: Editora 34, 1994.

METZGER, J. Paul; BUSTAMANTE, Mercedes; FERREIRA, Joice. Por que o Brasil precisa de suas reservas legais. Perspectives in Ecology and Conservation. Rio de Janeiro, v. 17, n. 3, p. 104-116, Julho-Setembro 2019.

OLSON, Sarah H.; GANGNON, Ronald; SILVEIRA, Guilherme Abbad; PATZ, Jonathan A. Deforestation and Malaria in Mâncio Lima County, Brazil. Emerging Infectious Diseases. Washington, v. 16, n. 7, p. 1108-1115, Julho 2010.

SERRES, Michael. O contrato Natural. Lisboa, Piaget, 1994. 